\title{
La extensión del federalismo sobre el desierto argentino. Los debates parlamentarios en la sanción de la Ley de Territorios Nacionales (1884)\%
}

\author{
The Extension of Federalism on the Argentine Desert. \\ Parliamentary Debates on the Sanction of the Law \\ of National Territories (1884)
}

\section{Lisandro Gallucci}

Universidad Nacional de San Martín

En 1884, la organización de los Territorios Nacionales, espacios carentes de autonomía y bajo el control de las autoridades federales, dio lugar a que se desarrollaran en el Congreso importantes debates en torno al régimen federal argentino y a la futura incorporación de los primeros en este último. El objetivo de este trabajo consiste en explorar las formas que tomó la relación entre federalismo y representación en el caso de los Territorios. Con el propósito de analizar los argumentos que alrededor de tales cuestiones desplegaron los legisladores que participaron en la sanción de la Ley de Territorios, el trabajo se concentra deliberadamente en la coyuntura de 1884.

Palabras Clave: Territorios Nacionales; Federalismo; Argentina; Siglo XIX.

In 1884, the organization of the National Territories, spaces lacking of autonomy and under control of federal authorities, gave place to important debates in the Congress about the Argentine federal regime, and the future incorporation of the first ones to the latter. The aim of this paper consists to explore the forms assumed by the relation between federalism and representation in the case of the Territories. With the purpose to analyze the arguments displayed by the legislatives that participated in the sanction of the Law of Territories, the paper deliberately focuses on the conjuncture of 1884.

KEYWORDS: National Territories; Federalism; Argentina; Nineteenth-Century.

* Este artículo fue elaborado en el marco de una Beca Puente de la Universidad Nacional de San Martín, Argentina. 
Las campañas militares desarrolladas en los ámbitos pampeano y patagónico no solo implicaron el sometimiento de las sociedades indígenas allí existentes. La incorporación de estos colocó a la joven República frente al desafío de diseñar una trama institucional para gobernar los nuevos dominios. El problema ya había surgido en el contexto de la guerra de la Triple Alianza, durante la cual el Estado argentino buscó afirmar su soberanía sobre el espacio chaqueño, propósito en función del cual se creó la gobernación del Chaco. La ley por la que fue establecida en 1872, la puso bajo el control directo del Estado nacional, sin dejar de precisar que la normativa mantendría vigencia hasta la sanción de una Ley General de Territorios Nacionales. En 1878, la creación de la gobernación de la Patagonia respondió a las necesidades de la ofensiva preparada desde el Estado nacional sobre dicho espacio, pero en lo sustancial implicó la reproducción de la misma estructura vigente en la del Chaco, con lo que el problema de la organización de los Territorios continuó sin resolución definitiva. Otra ley específica, sancionada en 1881, daría lugar a la creación de una nueva gobernación federal en Misiones, sin resolver tampoco el tema.

No fue sino hasta después de la incorporación efectiva de los espacios pampeano y patagónico, que la necesidad de dotar a las gobernaciones federales de una organización institucional más acabada adquirió un cariz más urgente. En base a un proyecto formulado por el Ejecutivo Nacional en 1883, en octubre de 1884 fue sancionada la ley 1532. Además de dividir las gobernaciones del Chaco y de la Patagonia en nuevas unidades territoriales, ${ }^{1}$ la normativa legislaba sobre una serie diversa de cuestiones relativas a los Territorios, que iban desde las facultades y características de sus funcionarios hasta precisiones respecto de la administración de justicia y las capacidades fiscales de los municipios, entre muchos otros aspectos. A través de dicha ley se pretendía dar una nueva organización institucional a espacios que solo habían contado con gobernaciones que habían servido al propósito de afirmar la autoridad del Estado nacional en extensas áreas de frontera. La sanción de la ley 1532 constituyó una novedad, no solo en la medida que estableció un régimen de gobierno y administración de las

1 Mediante esa ley la gobernación del Chaco (1872-1884) fue dividida en los Territorios Nacionales del Chaco y de Formosa, mientras que la gobernación de la Patagonia (1878-1884) dio lugar a los Territorios de Neuquén, Río Negro, Chubut, Santa Cruz y Tierra del Fuego. A diferencia de estos casos, el Territorio de Misiones, creado en 1881, mantuvo los límites originales con la única excepción de la incorporación de la ciudad correntina de Posadas, en 1883. En adelante, todas las menciones a la ley 1532 y otras afines a los Territorios Nacionales provienen de Reyna, 1914. 
poblaciones que se preveía habrían de formarse en los nuevos espacios, sino porque también contemplaba la futura incorporación de estos últimos al sistema federal. En efecto, la ley finalmente sancionada establecía que cuando un Territorio alcanzara los treinta mil habitantes - comprobados a través de censos oficiales - accedería a la posibilidad de formar su propia legislatura, mientras que al doblar esa cifra podría ser transformado en una provincia autónoma. Esto significaba que los Territorios creados en los espacios recientemente incorporados debían ser ulteriormente igualados a las provincias, gozando de las mismas prerrogativas que estas.

En las últimas dos décadas, una creciente cantidad de trabajos se ha ocupado de analizar diversos aspectos relativos a la historia política de los Territorios, siendo más abundantes los estudios dedicados a los del sur del país que a los del norte. ${ }^{2}$ Pero más allá de los diferentes casos y perspectivas de análisis utilizadas por los distintos investigadores, parece posible entender que existe en la historiografía sobre Territorios un supuesto bastante extendido en cuanto a la forma de interpretar la normativa establecida sobre aquellos espacios. En particular, dichos estudios han coincidido en describir al orden institucional de los Territorios como marcado por un carácter restrictivo que, a su vez, habría sido típico del orden conservador inaugurado en 1880. Desde esta perspectiva, los Territorios Nacionales habrían constituido entidades sujetas a un «republicanismo tutelado», ${ }^{3}$ según el cual la población de aquellas regiones habría sido considerada como portadora de incapacidad política. ${ }^{4}$ Ese juicio negativo habría servido para justificar la exclusión política de los habitantes de los Territorios, ${ }^{5}$ y también la demora en la transformación de estos en provincias autónomas. ${ }^{6}$ A partir de esas lecturas, algunos trabajos han propuesto que, la carencia de autonomía y de representación política que caracterizaba a los Territorios, habría sido expresión de un régimen de «colonialismo interno», ${ }^{7}$ cuya vigencia explicaría la tardía provincialización de aquellas gobernaciones en la década de 1950.

2 Sin pretensión de exhaustividad, entre esas producciones cabe mencionar: Arias Bucciarelli, 1996; Favaro y Arias Bucciarelli, 1995; Favaro, 1996 y 2007; Leoni, 2001 y 2002; Ruffini, 2006 y 2007a; Girbal-Blacha, 2011.

3 Ruffini, 2007a, 65.

4 Favaro, 1996 y 2007; Ruffini, 2007a.

5 Ruffini, 2007b y 2009.

6 Ruffini y Pravato, 2011.

7 Berhongaray, 2000; Navarro Floria, 2007; Zusman, 2010. 
El principal problema de estas interpretaciones radica en que pretenden comprender la tardía transformación de los Territorios en provincias a partir de los principios que según ellas articularían el orden institucional establecido en la ley 1532. De este modo, la evolución política que mostraron los Territorios luego de su creación en 1884, evidenciaría la persistencia de ciertas concepciones negativas acerca de los habitantes de aquellos espacios y en definitiva la vigencia de una serie de postulados restrictivos que guardarían exacta correspondencia con el modelo de la «República posible». Si bien la imagen de esta última merecería ser revisada críticamente, ${ }^{8}$ basta aquí con señalar la conveniencia de distinguir entre al menos dos planos del problema relativo al estatus político de los Territorios. Por una parte, el orden institucional que se pensó para aquellos espacios en el preciso momento legislativo de 1884; por la otra, las formas cambiantes en que dicha normativa fue interpretada y aplicada en los años posteriores a su sanción. Sin intención de abordar aquí esto último, en el presente trabajo nos proponemos explorar la primera de las dimensiones señaladas, pero limitando a su vez la mirada a ciertos aspectos puntuales de los debates que se produjeron en el Congreso al sancionarse la ley 1532. Esto significa renunciar a un análisis pormenorizado de cada una de las prescripciones contenidas en dicha ley, puesto que las mismas abarcan una serie tan diversa de cuestiones que impide ocuparse de todas ellas en estas páginas. ${ }^{9}$

Abordar los debates parlamentarios en torno a la ley 1532 no supone avanzar por alguna suerte de terra incognita, sino todo lo contrario. En casi toda la historiografía dedicada a los Territorios abundan las referencias a la organización institucional de estos últimos, destacando por lo general que dicha ley suponía la introducción de un régimen de gobierno opuesto al federalismo, en la medida que aquellos espacios carecían de autonomía y de representación en el Congreso. Pero en lugar de asumir esa caracterización como algo ya comprobado, en este trabajo nos proponemos reflexionar en torno a lo que la creación de los Territorios implicaba para el sistema federal de representación consagrado en la Constitución nacional. En particular, interesa reflexionar en torno a los siguientes interrogantes: ¿cómo resolvie-

8 De acuerdo con Palti, al ser adoptadas sin una mirada suficientemente crítica, las figuras de las Repúblicas «posible» $\mathrm{y}$ «verdadera» han dado lugar a concepciones fuertemente teleológicas de la historia política argentina del siglo XX. Palti, 2009.

9 Por otro lado, la pretensión por ofrecer un recuento detallado de todas las cuestiones comprendidas en la ley 1532 no ha dado lugar más que a aproximaciones puramente descriptivas que no problematizan la sanción de dicha normativa. Ejemplos de esto en: Farías de Foulkes, 1976 y 1977; Rebollo Paz, 1974. 
ron los legisladores de 1884 la cuestión de la futura incorporación de los Territorios al sistema federal de representación? ¿Hasta qué punto el régimen de gobierno establecido para los Territorios en la ley 1532 se mostraba contrario al federalismo, entendido — - según una definición clásica- como una forma de organización política en la que las actividades de gobierno están divididas entre los gobiernos locales y el gobierno central? ${ }^{10}$

Para explorar estas cuestiones nos detendremos en los debates parlamentarios desarrollados en torno a la ley 1532 y, en particular, en dos asuntos pertinentes a la problemática formulada. Por una parte, la propia delimitación geográfica de los Territorios, que implicaba al mismo tiempo definir los de algunas provincias y también la relación de estas con el Estado nacional. Por la otra, la fallida propuesta oficial de otorgar a los Territorios una forma especial de representación parlamentaria, iniciativa cuyo rechazo final en el Congreso expresa problemas más complejos que la supuesta voluntad de los legisladores por restringir los derechos de la población. Sin agotarse en ellas el debate parlamentario, ambas permiten observar dimensiones del federalismo argentino que iban inclusive más allá de la condición particular de los Territorios.

Es importante insistir en la posibilidad de una mirada concentrada en la coyuntura de la sanción de esa ley, puesto que un abordaje semejante permite dar cuenta de los consensos, pero también de las diferencias manifiestas en los argumentos de los legisladores. Reconstruir al menos parte de esa heterogeneidad no implica desatender el contexto en el que se produjo la organización de los Territorios, pero tampoco obliga a analizar las interpretaciones que se hicieron en torno al estatus institucional de esos espacios con posterioridad a su creación y menos aún a explorar las prácticas administrativas a que dio lugar su aplicación. Si bien existen numerosos trabajos que se han ocupado de analizar diversos rasgos de la ley 1532, entendemos que la mayoría han alimentado una imagen demasiado unívoca de una serie de temas y problemas que en realidad obligan a introducir algunos matices. Con ese propósito, el presente artículo ofrece en primer término un esbozo del contexto general en el que tuvo lugar la organización de los Territorios. Luego de esto se exploran dos cuestiones relevantes para comprender el lugar asignado a dichos espacios dentro del régimen federal argentino: por un lado, la relativa a la definición de los límites de los Territorios; por otro, la posibilidad de su representación en el Congreso de

10 Riker, 1975, 101. 
la nación. A partir de esas observaciones, el artículo se cierra con algunas reflexiones finales en torno a la necesidad de contemplar la diversidad de sentidos que puede albergar el concepto de federalismo.

\section{Los Territorios en la órbita de la nación}

El hecho de que las extensiones que se encontraban más allá del ámbito de las catorce provincias fueran reclamadas como propias por la nación y luego puestas bajo la administración del Estado argentino, constituyó una dimensión muy significativa de su consolidación. ${ }^{11}$ Por primera vez en su breve historia, este lograba extender - aunque con limitaciones - sus capacidades de gobierno hacia el conjunto del territorio sobre el que reclamaba soberanía. Como ya fuera mencionado, hasta la llegada de esos tiempos, vastos espacios al norte y al sur del país habían sido reivindicados como parte de la nación pero en realidad permanecían bajo el dominio efectivo de las sociedades indígenas.

Pero, ¿por qué esas regiones, que en conjunto terminaron representando prácticamente la mitad de la actual superficie nacional, fueron puestas en la órbita del Estado nacional? La normativa producida a partir de 1853 fue prefigurando ese destino: la Constitución aprobada ese año fijaba como una de las atribuciones del Congreso de la nación la de organizar y gobernar los espacios que se encontraban más allá de los límites de las provincias, aunque estos no estaban definidos con claridad. Por otro lado, la ley 28 de 1862 estableció la propiedad exclusiva de la nación sobre aquellos espacios, lo que puso freno a las ventas especulativas que muchas provincias venían practicando sobre los espacios de frontera. ${ }^{12}$ Las gobernaciones de Chaco, Patagonia y Misiones — creadas en 1872, 1878 y 1881 respectivamente-, no hicieron más que ratificar en la práctica la potestad que la nación tenía para administrar aquellos espacios, aun cuando en gran medida estos se encontraban fuera de su control efectivo. Por supuesto, dar cuenta de esa legislación no basta para explicar por qué razones fue el Estado nacional el que asumió el gobierno de espacios tan extensos como distantes de los centros de decisión política.

11 Entre muchos otros: Halperin Donghi, 1995, 100; Oszlak, 2006, 110.

12 Ruffini encuentra a esa ley como expresión de un Estado federal que «avasallaba [...] las autonomías provinciales» y como «un signo de omnipotencia estatal, al percibir que solo el Estado nacional estaba en condiciones de poblar y ocupar esas tierras, sin considerar la experiencia provincial al respecto». Ruffini, 2007a, 38. 
Se ha dicho con razón que una de las preocupaciones más importantes para los constituyentes de 1853 radicaba en crear una esfera de poder diferente y superior a la de las provincias. A partir de un conjunto de unidades políticas autónomas, el desafío más importante era el de crear un centro capaz de imponer sus decisiones sobre las primeras, proceso que da cuenta de una similitud entre la construcción de los federalismos estadounidense y argentino. ${ }^{13} \mathrm{La}$ emergencia de una esfera de poder federal con capacidad para prevalecer sobre las provincias no resultó sencilla ni libre de conflictos, ${ }^{14}$ pero se fue produciendo a través de un juego complejo signado por la violencia y el acuerdo. El aumento de las capacidades de ese emergente Estado federal tuvo lugar gracias a la concentración de una serie de recursos, tanto institucionales como materiales, a la que contribuyó también la nacionalización de los espacios que se abrían más allá del alcance de las provincias.

Hay, sin embargo, otros elementos que deben ser tenidos en cuenta para comprender por qué los nuevos espacios fueron puestos bajo la administración del Estado nacional. Cabe recordar que, como numerosos trabajos han mostrado, las representaciones sociales acerca de aquellas regiones las mostraban como desiertos, en el sentido que carecían de población civilizada. ${ }^{15}$ Fuera de algunos pequeños, escasos y aislados centros de población, la realidad de los espacios que se extendían más allá de las provincias no parecía más que confirmar aquella imagen dominante. No es que se ignorara que esos espacios estaban habitados por indígenas, pero las formas de organización social de estos no se correspondían con las que eran consideradas propias de la civilización. De manera que ese reconocimiento no introducía duda alguna sobre aquella representación de los espacios chaqueño, pampeano y patagónico. Frente a ese escenario, resultaba inconcebible la posibilidad de organizar en lo inmediato algún tipo de gobierno autónomo en aquellas regiones. Sin que existiera una población posible de ser representada políticamente, los nuevos espacios debían ser

13 En los Estados Unidos, Hamilton, Madison y Jay constituyeron los referentes más claros de esa preocupación. Hamilton, Madison y Jay, 2000.

14 Según Botana, durante la segunda mitad del siglo XIX el principal conflicto que atravesó la construcción del federalismo argentino se dio entre el gobierno federal y las provincias más poderosas, especialmente la de Buenos Aires, que se incorporó más tardíamente a ese régimen federal. Botana, 1993, 233. Otras miradas, como las de Gibson y Faletti, ponen mayor énfasis en la dimensión interprovincial de los conflictos que atravesaron la construcción del federalismo argentino. Como estos últimos autores mencionan, ambas perspectivas son más complementarias que antitéticas. Gibson y Falleti, 2007, 198.

15 Quijada, 2000; Livon Grosman, 2003; Rodríguez, 2010. 
provisoriamente puestos bajo el gobierno del Estado nacional que tenía potestad sobre esas tierras.

Algunas miradas encuentran en la organización de los Territorios Nacionales en 1884 un signo inequívoco de la dirección centralizadora que algunos sectores buscaban imprimir al federalismo argentino. Sin que esto sea incorrecto, es necesario reflexionar sobre qué otras alternativas podían existir para establecer el gobierno y la administración de tan extensas y distantes regiones del país. ¿Habrían podido las provincias asumir el gobierno de esas regiones que, según se verá más adelante, algunas de ellas reclamaban como propias?

En primer lugar, había razones de orden práctico que lo hacían muy difícil. La más importante de ellas es que ninguna de las provincias podía asumir la administración de unos espacios que superaban largamente su disponibilidad de recursos y sus mecanismos de control. La mejor comprobación de esto radicaba en que la secular cuestión de la frontera con el indígena solo había podido ser resuelta por la acción del Estado nacional, a partir de $1879 .{ }^{16}$ Aun cuando reivindicaban títulos sobre porciones más o menos extensas de esos espacios, lo cierto es que ninguna de las provincias había podido por sí sola asegurar un control efectivo de aquellas regiones, que hasta la década de 1880 continuaban dominadas por los indígenas. Durante los debates de 1884 en torno a la Ley de Territorios, el punto fue advertido por Bernardo de Irigoyen —entonces a cargo del Ministerio del Interior y vocero del proyecto del Ejecutivo-,${ }^{17}$ al señalar que no habían sido las de ninguna provincia sino «las armas de la Nación, las que han conquistado esos territorios, para incorporarlos al trabajo de todos: al tra-

16 Por supuesto, esto no significa que la cuestión de la frontera con el indígena tuviera una rápida resolución. Si es posible entender que así ocurrió en los espacios pampeano y patagónico, donde los grupos indígenas se encontraban sometidos ya para mediados de la década de 1880, no ocurrió lo mismo en la región chaqueña, donde el sometimiento de las poblaciones indígenas recién se concretaría entrado el siglo XX. En relación con la cuestión indígena al sur y al norte del país, cabe consultar entre otros: Iñigo Carrera, 1988 y Mases, 2010.

17 Bernardo de Irigoyen fue una destacada figura de la política argentina de la segunda mitad del siglo XIX. Nacido en Buenos Aires en 1822 y más tarde graduado en Derecho, Irigoyen transitó por distintos cargos públicos, entre los que cabe destacar su desempeño como ministro —de Relaciones Exteriores y del Interior - tanto en la presidencia de Avellaneda como en la de Roca. Fue desde la cartera del Interior desde donde Irigoyen buscó ubicarse como candidato a la presidencia en 1886, aunque sin éxito debido entre otras razones a que no contó con el apoyo de Roca. Irigoyen formó parte de la Unión Cívica y participó en la Revolución del Parque que puso fin al gobierno de Juárez Celman. Luego de romper con el mitrismo, en 1892 Irigoyen fue postulado como candidato a la presidencia por la Convención de la Unión Cívica Radical. Fue luego gobernador de la provincia de Buenos Aires y senador nacional por la misma. Esta referencia biográfica, como todas las que se hacen a lo largo del artículo, provienen de Cutolo, 1968-1985. 
bajo de las provincias, al trabajo de la Nación».$^{18}$ Los cuestionamientos de algunos legisladores, que señalaban que la administración de los Territorios sería forzosamente ineficiente debido a la distancia que los separaba de la capital federal, estaban muy lejos de convencer a sus pares de que aquellos vastos y alejados espacios podrían ser mejor gobernados por las provincias.

Pero más importante que esa controversia en torno a la capacidad efectiva del Estado nacional para gobernar aquellos espacios resulta el hecho de que existían razones institucionales y doctrinarias que condujeron a que los Territorios quedaran bajo el control de aquél. La posibilidad hipotética de que esos espacios fueran administrados por las provincias no podía sino introducir problemas en el federalismo argentino, en la medida que el acrecentamiento de los dominios de algunas de ellas produciría distorsiones - aún mayores de las existentes - en dicho sistema de gobierno. La propia prescriptiva constitucional llevaba a que los nuevos espacios fueran organizados de modo tal que dieran lugar al surgimiento de nuevas provincias, lo que suponía no destinarlos al incremento territorial de las ya existentes. En lugar de profundizar por este último camino las asimetrías entre las provincias, la solución que desde un federalismo liberal se imponía frente al problema de los Territorios apuntaba en la dirección de multiplicar los miembros de la federación en lugar de aumentar el poder de los que formaban parte de la misma. ${ }^{19}$ Durante los debates parlamentarios en torno a la sanción de la ley 1532, Nicolás Calvo, diputado por la capital federal, afirmaba que «mientras más provincias tengamos, mayor garantía tendrá la Nación de continuar en el sistema federal de gobierno que se halla en vigencia», y para esto entendía necesario «que las provincias no se hagan más grandes en su extensión, sino más pequeñas, o queden como están». ${ }^{20}$ Para Calvo, un estudioso de la Constitución estadounidense y sus

18 Congreso Nacional de la República Argentina, Diario de Sesiones de la Cámara de Diputados, 1884, Buenos Aires, Imp. y Encuad. de Stiller \& Laas, 1885, Tomo I, 1119. En adelante toda referencia a los diarios de sesiones del Congreso Nacional se hará bajo las siglas DSCD, para la Cámara de Diputados, y DSCS, para la de Senadores.

19 Las observaciones de Tocqueville acerca del federalismo estadounidense son particularmente claras en cuanto a su efecto moderador del poder. Tocqueville, 2005.

20 DSCD, 1884, I, 1135. Nacido en 1817, Calvo tuvo una intensa actividad política que combinó la banca legislativa con la labor periodística. Tuvo especial preocupación por el federalismo, especialmente en cuanto a la experiencia de los Estados Unidos. En diferentes obras, Calvo se ocupó de introducir el pensamiento de importantes constitucionalistas norteamericanos como Joseph Story, traduciendo y comentando en 1864 sus Commentaries on the Constitution of the United States (1833), y George Washington Paschal, haciendo en 1888 lo mismo con The Constitution of the United States (1868), agregando también sus comentarios propios. 
comentaristas, la República Argentina debía encarar el problema de la organización institucional de los Territorios siguiendo la experiencia del país del norte, cuya formidable expansión territorial había dado lugar a la multiplicación de los estados miembros de la Unión y en su opinión afianzado las bases del sistema federal.

Es cierto que la formación futura de nuevas provincias en los Territorios suponía en lo inmediato poner a estos últimos bajo la égida exclusiva del Estado nacional. Esto ha llevado a entender al sistema de gobierno establecido en la ley 1532 como uno de carácter unitario y por lo tanto opuesto a la tradición y las instituciones propias del federalismo. ${ }^{21}$ En la medida que dicha normativa no otorgaba autonomía ni representación a los Territorios que organizaba, aquella caracterización parecería justificada. No obstante, y sin desconocer la orientación centralizadora del «nacionalismo unificador» que caracterizó a la primera presidencia de Julio A. Roca, ${ }^{22}$ es necesario llamar la atención sobre el hecho de que la misma ley que organizaba los Territorios, establecía su futura incorporación al sistema federal en calidad de provincias autónomas. El camino en esa dirección era gradual: al alcanzar los treinta mil habitantes un Territorio podía formar su legislatura, mientras que al llegar a sesenta mil podía ser convertido en una provincia. La sujeción de los Territorios al Estado federal era solo transitoria.

Que aquellas previsiones no se cumplieran en las décadas posteriores, aun cuando algunos Territorios fueron superando esos umbrales demográficos, ha obstruido el reconocimiento del horizonte federal que la normativa nunca dejó de marcar para aquellas gobernaciones. Esto ha llevado a que gran parte de la historiografía dedicada a los Territorios se inclinara a buscar la explicación de esa tardía provincialización en los principios que considera plasmados en la ley 1532. Pero en lugar de suscribir esa suerte de mirada genealógica —engañosa en múltiples sentidos-, es necesario distinguir entre, por un lado, el diseño institucional que se montó para los Territorios en 1884 y, por el otro, los avatares que el mismo experimentó en las décadas posteriores, aspecto este que no se intenta abordar en este trabajo. Lo que sí interesa destacar es que no debe perderse de vista que la ley 1532 contenía una clara promesa de autonomía para los Territorios. De manera que si bien

21 Botana señala como «organización unitaria» a la que se estableció sobre los Territorios Nacionales en 1884. Botana, 1993, 241. Para Ruffini, los Territorios eran «verdaderas cuñas unitarias». Ruffini, 2007b, 83. Más enfática llega a ser la mirada de Moroni, para quien «la incompatibilidad manifiesta que existía entre la ley 1532 y la Constitución nacional rozaba la ilegalidad». Moroni, 2007, 210. 22 Botana y Gallo, 1997, 29. 
es cierto que en lo inmediato dicha normativa colocaba a los Territorios bajo el control provisorio del Estado nacional, también lo es que el destino que marcaba para aquéllos era el de su futura transformación en provincias en pie de igualdad con las existentes. Esto sugiere que el orden institucional fijado en la ley 1532 no expresaba tanto una negación del régimen federal, sino más bien un modo de preparar la extensión de este último hacia el conjunto de la nación. Podía tratarse de un federalismo que algunos autores caracterizan como centralizador, ${ }^{23}$ pero el horizonte establecido por la ley 1532 encajaba más que contradecía con aquel sistema de gobierno.

No advertir la importancia de esto ha llevado a postular, por ejemplo, que los Territorios fueron concebidos como «colonias internas» por un Estado nacional deseoso por emular las experiencias imperiales de finales del siglo XIX. ${ }^{24}$ El hecho de que mediante la ley 1532 se organizara a los Territorios como espacios sin autonomía ni representación en el Congreso daría cuenta de una mirada «colonial» que deliberadamente negaba a aquellos espacios los beneficios del régimen federal. ${ }^{25}$ Pero es que la prescriptiva federal que encerraba la ley 1532 al sancionar el destino provincial al que debían llegar los Territorios, obliga a reconocer la absoluta diferencia entre el modelo institucional adoptado para estos últimos y los regímenes de dominación colonial en los que por defecto no existía promesa alguna de autonomía futura y menos aún sujeta a un criterio puramente cuantitativo como el que definía aquella normativa. Aún atravesado por una creciente centralización, el sistema federal consagrado en la Constitución impedía concebir a los espacios incorporados a la nación como dominios coloniales posibles de ser mantenidos en tal condición sin término alguno. En relación con la expansión territorial de los Estados Unidos, se ha señalado que lo más importante de ella es que se llevó adelante desde el rechazo al modelo de subordinación colonial de los nuevos dominios. De acuerdo con Bender, «la Ordenanza del Noroeste y luego la Constitución prometieron igualdad entre los viejos y nuevos estados», ${ }^{26}$ lo que contrastaba fuertemente con el modelo imperial de dominación desplegado por las naciones europeas en sus dominios ultramarinos.

23 Gibson y Falleti, 2007.

24 Zusman, 2000, 61.

25 Para Navarro Floria, los Territorios denotaban la existencia de una «inadecuación entre el régimen político de colonialismo interno impuesto por la ley 1532 y una Constitución Nacional formalmente federal». Navarro Floria, 2009, 91.

26 Bender, 2011, 117. 
No puede dejar de subrayarse la importancia de este punto dado que, como es ampliamente conocido, la organización que la Argentina definió para sus Territorios Nacionales abrevó fuertemente de la experiencia norteamericana. Los debates suscitados en torno a la sanción de la ley 1532, con frecuentes referencias a los Estados Unidos y su modelo federal, dan cuenta de la relevancia que para los legisladores argentinos tenía el modelo de expansión territorial del país del norte. Pero además de esa influencia, eran las propias instituciones políticas establecidas en la Argentina a partir de 1853, y en particular su régimen federal, lo que orientaba a concebir a los Territorios como provincias futuras y no como simples dominios coloniales.

\section{El problema de los límites}

El desenvolvimiento del régimen federal argentino durante la segunda mitad del siglo XIX ha sido descrito como «un sostenido proceso de reducción de las provincias a la unidad del Estado». ${ }^{27}$ Esta imagen parece ajustarse al recorrido del Estado nacional argentino durante ese período, caracterizado por la acumulación por aquél de una cantidad creciente de capacidades, pero además guarda relación con la forma en que pensadores como Alberdi entendieron el problema de la construcción del primero. En su Bases, de 1852, el tucumano reflexionaba: «¿Qué es la unidad o consolidación del gobierno? Es la desaparición, la absorción de todos los gobiernos locales en un solo gobierno nacional».28

Sin embargo, desde su constitución en 1853, ese Estado asumió un sistema federal de organización política que, más allá de los avatares que conocería en las décadas posteriores, nunca fue sustituido por un régimen de otro tipo. Aun cuando en su funcionamiento efectivo el federalismo argentino mostró una orientación centralizadora — que fue objeto de denuncia por algunos contemporáneos- ${ }^{29}$ aquel sistema institucional no dejó de tener efectos sobre la vida política del país. Aunque sería equivocado pensar a las provincias como actores coherentes y racionales, el régimen federal proporcionó a los representantes de aquéllas un lugar desde donde fue posible mantener con el Estado nacional relaciones que iban más

27 Botana, 1993, 235.

28 Alberdi, 1915, 134-135.

29 Gallo, 2009. 
allá de la mera subordinación. En este sentido, resulta sugestivo pensar el proceso de construcción de este último no como resultado del sometimiento de múltiples poderes - las provincias - a un poder superior que las absorbe haciéndolas desaparecer - lo que nunca ocurrió-, sino como producto de los conflictos y los acuerdos mantenidos entre todas esas partes. Como señalan Bragoni y Míguez, vista desde esa perspectiva, la consolidación del Estado nacional durante la segunda mitad del siglo XIX

no aparece como la penetración de un actor ajeno que las va conquistando o sometiendo, sea este Buenos Aires o un abstracto centro nacional, sino más bien como la construcción de un conjunto de acuerdos y de instituciones que las propias elites provinciales establecieron sobre la base de un ejercicio político empírico de ensayo y de error. ${ }^{30}$

En otros términos, el tono centralista que fue adquiriendo el país durante aquel período se dio dentro de un sistema institucional —el federalismo- que hizo de las provincias unidades en última instancia irreductibles a la unidad del Estado federal.

Las discusiones desarrolladas en torno a la ley 1532 permiten observar algunos aspectos que invitan a matizar la imagen de un Estado nacional que sencillamente se impone sobre las provincias, y a sugerir otra en la que aquel negocia con estas últimas según la configuración del juego de alianzas existente en una determinada coyuntura. Uno de los puntos donde esta cuestión puede ser observada es en lo relativo a la definición de los límites de los Territorios, lo que implicaba a su vez fijar los de las provincias contiguas a estos últimos. Las gobernaciones de Chaco y de Patagonia permanecieron sin límites precisos hasta 1884, cuando la sanción de la ley 1532 no solo implicó la división de ambas en nuevos Territorios, sino también el establecimiento de límites específicos para cada uno de estos. ${ }^{31} \mathrm{Si}$ bien la mayoría de los análisis de la ley 1532 no dieron demasiada importancia al asunto de los límites de los Territorios - fuera de algunos enfoques puramente descriptivos- ${ }^{32}$ su demarcación estuvo lejos de constituir un aspecto marginal del debate parlamentario y de hecho constituyó uno de los puntos más que suscitó mayor controversia.

30 Bragoni y Míguez, 2010, 27.

31 Los límites que definió la ley 1532 reconocían como antecedentes a ley 686 de 1874 , en el caso de los Territorios del norte — con la excepción de Misiones_-, y a la ley 947 de 1878, en el caso de los Territorios del sur.

32 Rebollo Paz, 1974; Allende, 1980. 
De las siete sesiones que ocupó el tratamiento de la ley en la Cámara de Diputados, cinco estuvieron dedicadas en forma exclusiva a la discusión de dicho artículo, que volvió a ser debatido en la sesión en la que finalmente se aprobó el proyecto. Claro que la cuestión de límites no presentó el mismo grado de controversia en todos los casos. En particular, en aquellos destinados a separar a los nuevos Territorios entre sí, poca o ninguna fue la polémica a que se dio lugar. Por ejemplo, en los casos de los Territorios patagónicos no hubo discusiones acerca de los límites que separarían una gobernación de otra, lo que evidencia que los legisladores concebían aquel espacio como un enorme vacío donde los límites podían trazarse sin resistencia alguna. En cambio, los límites relativos a los Territorios de La Pampa, Chaco y Formosa dieron lugar a encendidas intervenciones por parte de diputados que denunciaban los supuestos despojos que el Estado nacional provocaba contra las provincias limítrofes.

Para los legisladores más críticos del proyecto oficial, este representaba un intento más del gobierno nacional por imponer su poderío sobre la soberanía de las provincias, que llegaba al extremo de privarlas de parte de sus respectivos territorios. Ya se mencionó que el establecimiento de los límites interprovinciales permanecía sin resolución para 1884 y la delimitación propuesta en el proyecto de ley llevaba a algunos a ver en esta un medio oportunista para resolver la primera cuestión. Esto hacía que legisladores como el diputado por Santa Fe, Aureliano Argento, afirmaran que antes de ocuparse de la creación de nuevas entidades, era primero necesario considerar todos los títulos que cada provincia podía hacer valer en torno a territorios reclamados como propios..$^{33} \mathrm{La}$ misma idea de una apropiación ilegítima del territorio provincial por parte del Estado federal era sostenida por los diputados por Salta y por Santiago del Estero, que también entendían afectada la soberanía de sus provincias. Abel B. Ortiz, diputado por la primera, calificaba de «monstruoso», «inconstitucional» y «escandaloso» el límite con el Territorio del Chaco propuesto en el proyecto oficial. ${ }^{34} \mathrm{~A}$ estos reclamos se incorporaban los vertidos por los

33 DSCD, 1884, I, 1073. Nacido en Santa Fe en 1838, Argento se graduó como abogado en Montevideo y tras retornar a su provincia natal, se desempeñó en la administración de justicia de la misma. Formó parte de la intervención federal que la presidencia de Mitre estableció sobre Santa Fe en 1868 y durante la década siguiente ocupó puestos ministeriales en el gobierno provincial. Entre 1873 y 1886 ocupó bancas en el Congreso de la nación, tanto en calidad de diputado como de senador.

34 DSCD, 1884, I, 1083. Ortiz nació en Salta en 1850 y se graduó como abogado en la Universidad de Buenos Aires. Tuvo una actuación destacada en el ámbito jurídico de su provincia y fue diputado nacional por la misma entre 1882 y 1886. 
diputados por Mendoza y por San Luis, provincias a las cuales, en opinión de Germán Puebla — diputado por la primera—, la delimitación propuesta para el Territorio de La Pampa implicaba «la supresión para ellas, de una parte importante de renta, como es la que estos territorios son susceptibles de dar»..$^{35}$

Para los legisladores que objetaban la división territorial propuesta por el Poder Ejecutivo, esta suponía un ilegítimo desconocimiento de los derechos de las provincias. En relación con los títulos sobre los espacios en discordia, el razonamiento de esos legisladores apuntaba a señalar la preexistencia de las provincias con respecto a la nación. Al invocar actas de fundación de las capitales de provincia o las ordenanzas de intendentes del período borbónico, buscaban validar legalmente los derechos de las provincias sobre ciertas regiones. ${ }^{36} \mathrm{Al}$ mismo tiempo, esos legisladores intentaban refrendar la fuerza del planteo señalando que las regiones objeto de controversia en realidad se encontraban desde hacía tiempo incorporadas a la vida social y económica de las provincias afectadas. No se trataba únicamente, según ellos, de actos de posesión efectuados por las autoridades provinciales - tanto en el período colonial como en el independiente-, sino también de los que surgían de la ocupación y el uso efectivo de esos espacios por particulares oriundos de esas provincias. ${ }^{37}$

No solo de estos argumentos se valían algunos legisladores para cuestionar los límites delineados en el proyecto oficial. Las críticas también apuntaban a la conveniencia misma de la creación de los Territorios, que algunos parlamentarios consideraban solo daría lugar a injustificadas y desproporcionadas erogaciones que el tesoro nacional debería realizar para el gobierno de espacios que contemplaban como vacíos. En tal sentido, el diputado Puebla entendía que la creación de gobernaciones en Neuquén, Río Negro y La Pampa, obligaría al gobierno nacional a

sostener un lujo de empleados completamente innecesarios, puesto que la mayor parte de las gobernaciones que se crean, no responden ni a una necesidad apremiante, ni a ninguna otra consideración que pudiera justificarlas. ${ }^{38}$

35 DSCD, 1884, I, 1085. Nacido en la provincia de Mendoza en 1850, Puebla se desempeñó inicialmente en el sistema judicial provincial, llegando a integrar el Superior Tribunal en 1877. Entre 1882 y 1886 fue diputado nacional por Mendoza.

36 DSCD, 1884, I, 1073 y 1142

37 Ibidem, I, 1151.

38 Ibidem, I, 1091. 
Al mismo tiempo, otros legisladores apuntaban a la ineficiencia con la que funcionarían las gobernaciones territoriales, por ser dependientes de autoridades nacionales extremadamente distantes de aquellas regiones.

De manera que tanto por razones presupuestarias como de eficiencia gubernamental, algunos legisladores entendían que el criterio más adecuado consistía en ampliar la jurisdicción de las provincias para que las mismas asumieran la administración de los espacios en disputa. Como proponía el diputado salteño Ortiz con relación a la región occidental de Formosa y de Chaco,

si la Nación conociera esos territorios y fueran nacionales, como se pretende, la Nación los cedería a la provincia de Salta, porque no podrían ser bien administrados por la Nación, ni ahora, ni nunca. ${ }^{39}$

Para quienes no consideraban pertinentes esas aspiraciones, como era el caso del ministro Irigoyen, los derechos que las provincias reclamaban eran inexistentes porque la conquista de la independencia había provocado la caducidad de todos los títulos emanados de la autoridad real. ${ }^{40}$ Frente al argumento de la conveniencia de que los Territorios quedaran bajo la administración de las provincias, otros diputados objetaban que las que reclamaban la ampliación de sus jurisdicciones no estaban en condiciones de responder a tal desafío, dada la escasez de sus recursos y las deficiencias de sus estructuras administrativas. ${ }^{41}$

Pero cabe advertir que las objeciones planteadas por algunos legisladores en torno a ciertos límites estuvieron lejos de ser declaraciones testimoniales sin mayor efecto, dado que sirvieron para modificar las demarcaciones establecidas en el proyecto original. El argumento más eficaz en tal sentido consistió en representar la circunstancia de la delimitación de los Territorios como una oportunidad para corregir las inequidades existentes entre las provincias argentinas. ${ }^{42} \mathrm{El}$ miembro informante del despacho de

39 Ibidem, I, 1087 y 1150.

40 Ibidem, I, 1089.

41 En este sentido, el diputado Calvo expresaba que «es materia de asombro para mí oír que los representantes de las provincias, piden aumento de territorio para ellas [...] una provincia que, siendo despoblada, no alcanza a cubrir su presupuesto de gastos; que no tiene absolutamente las condiciones que debiera tenerse, yo creo que, en vez de recibir un beneficio, recibe una carga que se le pone encima». Ibidem, I, 1087.

42 En tal sentido, advirtiendo que «la provincia de San Luis es sumamente pobre», el diputado Puebla sostenía que la misma «necesita extenderse igualmente á todos los rumbos desde su capital». Ibidem, I, 1085. 
comisión en la Cámara de Diputados, Ramón J. Cárcano, representante por Córdoba, veía con aprobación que el trazado original del Territorio de La Pampa fuera modificado para ceder a «tres provincias una pequeña superficie que realmente la necesitan [ya que] Córdoba, Mendoza y San Luis, que son provincias pobres, necesitan la pequeña área que piden». ${ }^{43} \mathrm{El}$ respaldo que este argumento recibió entre la mayoría de los legisladores sugiere la persistencia de una concepción liberal del federalismo, según la cual este implicaba ante todo un arreglo institucional destinado a equilibrar a las provincias entre sí. Para Juan Serú, diputado por Mendoza, el régimen federal debía estar animado por «un espíritu tendiente a equilibrar, en cuanto sea posible, las fuerzas diversas de las provincias, que han de formar esta armonía de elementos». ${ }^{44}$ Desde esa mirada, el federalismo implicaba ante todo un arreglo institucional de equilibrio del poder y cuya consolidación dependía del fortalecimiento de las provincias, sino de todas al menos de las que podían mostrarse como más necesitadas.

Aquellos argumentos parecen haber encontrado respaldo entre los demás diputados. La Cámara aprobó que los límites de las provincias de San Luis y de Mendoza con los Territorios adyacentes fueran alterados a favor de las primeras, lo que implicó la modificación de los que se habían establecido en 1878. ${ }^{45}$ En el caso del Territorio del Chaco, parte del oeste del mismo fue cedida a la provincia de Salta. Tales resoluciones no fueron revisadas en la Cámara de Senadores, donde la cuestión de límites no despertó mayores debates, probablemente por el criterio de provisionalidad que auspició la comisión que se ocupó de analizar el proyecto con las modificaciones introducidas por los diputados. Como señaló Miguel M.

43 Ibidem, I, 1086. En una intervención posterior, Cárcano declinó la petición para Córdoba, afirmando que esta última no tenía la misma necesidad de ver ampliado su territorio. Ibidem, I, 1137. Nacido en Córdoba en 1860, Cárcano formaba parte de los círculos juveniles ligados a Juárez Celman, cuyo gobierno lo promovió como diputado nacional en 1884. Cuando Juárez Celman llegó a la presidencia de la nación, Cárcano fue nombrado director general de Correos y Telégrafos de la nación, cargo que debió abandonar a raíz de los sucesos de 1890. Regresó al Congreso en 1910, como diputado nacional por Córdoba, provincia de la que sería elegido gobernador en 1913 y en 1925. En la década de 1930, presidió el Consejo Nacional de Educación y se desempeñó como embajador en Brasil.

44 DSCD, 1884, I, 1100. Nacido en San Juan en 1849, Serú fue diputado nacional por dicha provincia entre 1878 y 1882, mientras que ocupó el mismo cargo por Mendoza durante dos períodos (1884-1888 y 1898-1902). Ligado a los círculos roquistas, fue ministro de Instrucción Pública durante la segunda presidencia de Roca.

45 Según la ley 947 de 1878, los límites de San Luis y de Mendoza con las tierras nacionales estaban dados por el paralelo 35 y el meridiano 10 de longitud occidental de Buenos Aires. Este último fue mantenido, pero no así el primero, que fue desplazado hasta el paralelo 36, comportando ganancias territoriales para las provincias mencionadas. 
Nougués, senador por Tucumán, pese a los defectos que pudieran encontrarse en la cuestión de límites, concluía que «como es provisoria, no hiere ni los intereses de la Nación no los de las Provincias». ${ }^{46}$ Fue así que la ley finalmente sancionada planteó que los límites fijados en ella podían ser modificados ${ }^{47}$ lo que tiempo más tarde ocurrió en beneficio de algunas provincias. ${ }^{48}$

\section{El rechazo de la representación parlamentaria de los Territorios}

Si la resolución de la cuestión de los límites de los Territorios puede ser vista como expresión de las posibilidades de negociación que el régimen federal daba a las provincias, un punto para observar el lugar asignado a aquellas gobernaciones dentro del régimen federal es el relativo a su representación en el Congreso. Ya se mencionó que el proyecto elaborado por el poder ejecutivo en 1883 contemplaba la representación parlamentaria para aquellos Territorios donde funcionara una legislatura, para cuya formación debían contar con al menos treinta mil habitantes. Dicho delegado se incorporaría a la Cámara de Diputados, pero solo para intervenir en los debates y sin poder en ningún caso participar en las votaciones. La inclusión de esa figura en el proyecto del oficialismo revelaba una clara afinidad con la legislación norteamericana, y en particular el instituto de la representación a través del delegado era considerado un valioso instrumento para promover el progreso de los Territorios. ${ }^{49}$ Para quienes apoyaban la iniciativa prevista en el proyecto original, como José Miguel Olmedo, diputado por Córdoba, la incorporación de aquellos delegados al Congreso permitiría conocer las necesidades de dichas gobernaciones para legislar en

46 DSCS, 1884, 743. Nogués había nacido en Tucumán en 1844 y estudió en el Colegio Nacional del Uruguay junto al propio Roca. Ligado a la figura de Avellaneda, prestó un fuerte apoyo a Roca, cuyo gobierno prestó valiosa ayuda a Tucumán mientras Nogués fue gobernador de la misma, entre 1880 y 1883 . Desde esa fecha y hasta 1892, permaneció como senador nacional por dicha provincia.

47 El artículo $1 .^{\circ}$ de la ley establecía que las divisiones de los Territorios se hacían «sin perjuicio de lo que se establezca oportunamente por la ley general de límites».

48 Por ejemplo, en 1886 el límite sur del Chaco fue revisado a favor de la provincia Santa Fe. En 1902, los límites del primero volvieron a ser alterados, esta vez en beneficio de Santiago del Estero, traspasando a esta provincia el espacio noreste de su actual territorio.

49 Como señalaba el diputado Calvo, «hace casi cien años, desde 1797, que en la primera nación del orbe [Estados Unidos] se está mandando delegados al Congreso, por estados y territorios que se forman. Y con qué enorme, con qué extraordinario, con qué asombroso, con qué admirable éxito!». DSCD, 1884, I, 1216. 
consecuencia e impulsar su desarrollo y poder así «incorporarlas cuanto antes a la Unión nacional». ${ }^{50}$ Para Emilio Civit, diputado por Mendoza, la institución de tales delegados contribuiría a afianzar la organización institucional de la República al extender la representación al conjunto del país. ${ }^{51}$ En definitiva, desde esas miradas la figura del delegado territorial apuntaba a dar una representación supletoria a espacios que no contaban con autonomía política y que por consiguiente no podían gozar de representación plena en el orden federal.

Pese a la utilidad que muchos legisladores encontraban en los delegados, el proyecto del Ejecutivo no prosperó en este punto y la redacción final de la ley 1532 no incluyó esa figura. ¿A qué respondió ese resultado contrario a la organización institucional que inicialmente pretendió establecerse para los Territorios? Para algunos autores, esa negación del derecho de representación se explica porque los legisladores consideraban como incapaces a los habitantes de los Territorios y por lo tanto veían inaceptable su incorporación al Congreso. ${ }^{52}$ Más allá de las críticas que pueden plantearse a esa interpretación, las objeciones de quienes rechazaron la incorporación de los delegados territoriales al Congreso no partían de identificar ninguna incapacidad en los individuos que habitarían los Territorios - hacia 1884, las gobernaciones seguían siendo vistas como espacios despoblados-, sino que más bien reparaban en la condición institucional y política de tales espacios.

Para quienes la criticaban más fuertemente, la incorporación de esos delegados al Congreso violaba los mandatos constitucionales. En este sentido, Bernardo Solveyra, diputado por la provincia de Buenos Aires, señalaba el artículo 37 de la Constitución para destacar que el mismo era claro en ordenar que la Cámara de Diputados debía componerse exclusivamente de «representantes elegidos por el pueblo de las provincias y de la capital» y que, de incluirse en el recinto a los delegados territoriales, «tendríamos, en esta Cámara, individuos que no serían diputados! Serían seres

50 DSCD, 1884, I, 1214. Olmedo fue diputado nacional por Córdoba en forma casi continua entre 1880 y 1916, con la sola excepción de un periodo como diputado por la capital federal entre 1908 y 1912. Formó parte de los sectores más cercanos a Juárez Celman, pero la caída de este último no implicó el final de la carrera política de Olmedo.

51 DSCD, 1884, I, 1215. Nacido en Mendoza en 1856, Civit tuvo una destacada actuación política, estrechamente ligada al roquismo. No solo intervino en el ámbito legislativo sino también siendo elegido en dos oportunidades gobernador de Mendoza —en 1898 y 1907— y desempeñándose como ministro de Obras Públicas durante la segunda presidencia de Roca, dando un fuerte impulso al desarrollo de la infraestructura ferroviaria en el interior del país.

52 Ruffini, 2007a, 123. 
híbridos» ${ }^{53}$ Estas objeciones han sido interpretadas como expresión de una falta de sentido común,,$^{54}$ o como un ardid jurídico para justificar la negación del derecho de representación a los habitantes de los Territorios. ${ }^{55}$ Sin embargo, los argumentos contrarios a la creación de la figura del delegado territorial pueden ser entendidos de otro modo.

$\mathrm{Al}$ señalar que la Cámara de Diputados no podría incluir en su seno a representantes que no hubieran sido elegidos por el pueblo de las provincias o de la capital de la nación, los legisladores no solo encontraban ausentes a los Territorios de esa prescripción constitucional. En efecto, algunos parlamentarios no rechazaban en sí misma la inclusión de delegados territoriales en la Cámara, sino que apuntaban a las diferencias en la legitimidad de origen que separarían a esos representantes de los diputados. Si como mandaba la Constitución estos últimos debían ser elegidos por el pueblo de las provincias y la capital federal, los delegados territoriales contemplados en el proyecto del Ejecutivo iban a ser elegidos por las legislaturas de cada Territorio. ${ }^{56}$ Sin advertir esta cuestión no pueden entenderse las posiciones que al respecto asumieron algunos legisladores, como Puebla, quien señalaba que «dando el nombramiento de los delegados a las legislaturas, y no al pueblo, no se ha tenido en vista los buenos principios constitucionales», ${ }^{57}$ postulando que lo apropiado era confiarlos a la elección popular directa. Más clara resultaba todavía la posición de Olmedo, a quien le parecía conveniente contar con esos delegados en el Congreso, pero que votó en contra de su creación subrayando que «el origen de la representación en esta Cámara no debe estar en la entidad política llamada territorio, sino en el pueblo mismo». ${ }^{58}$ Como puede advertirse, las críticas de estos legisladores no apuntaban a rechazar de plano la creación de los delegados territoriales, sino a reconocer la existencia de una disparidad en cuanto a los objetos de representación presentes en la Cámara. Mientras que los diputados representaban al pueblo de las provincias, tal como eran

53 DSCD, 1884, I, 1213. Nacido en Buenos Aires en 1848, Solveyra estudió leyes y fue diputado por la provincia de Buenos Aires en dos períodos (1876-1880 y 1882-1886) y por la capital federal en una oportunidad (1880-1882).

54 Ruffini, 2007a, 123.

55 Pravato, 2011, 73.

56 Para Cárcano, la elección de los delegados por parte de cada legislatura territorial se justificaba porque «este delegado viene representando todo el territorio; y, entonces, su elección debe hacerse lo mismo que se hace, en las provincias, la de senadores al Congreso, por la Legislatura, puesto que no representan á la población, sino todo el territorio de la gobernación». DSCD, 1884, I, 1213.

57 DSCD, 1884, I, 1213.

58 DSCS, 1884, I, 1214. 
definidos en el proyecto oficial los delegados solo representarían una unidad espacial como el Territorio. Para otros diputados, el cambio en el método de elección no bastaba para aceptar la incorporación de los delegados a la Cámara. Según Miguel Navarro Viola, diputado por la capital federal, modificar la legitimidad de origen del delegado territorial no resolvía el problema, ya que la Constitución era taxativa al establecer que la Cámara se componía «de diputados con voz y voto; de diputados por las provincias, no de diputados ni de delegados por los territorios nacionales». ${ }^{59}$

En la mirada de otros legisladores, la carta magna ordenaba asegurar el derecho de representación a todo el pueblo de la nación, aun cuando para hacerlo efectivo se requiriese de la creación de instituciones y figuras inusuales como la de un delegado territorial con voz pero sin voto. A juicio de Olmedo,

la representación que deben tener todos los habitantes de la República falta a los de los territorios nacionales, y por eso se trata de dárseles en esta forma, un poco estraña porque también es estraña esta creación de estados incoados, que todavía no están en la perfecta posesión de todos sus derechos y de todas las facultades de tales. ${ }^{60}$

En su opinión, la Constitución establecía que los diputados no eran representantes del pueblo de las provincias sino del pueblo de la nación, de lo que derivaba que «no hay por qué privar a una fracción de ese pueblo del derecho de hacer oír su voz en el Congreso». ${ }^{61}$ De esta forma, entendía necesario que todos los Territorios, o al menos aquellos que alcanzaran los treinta mil habitantes, contaran con un delegado elegido en forma directa por su población.

Pese a haber sido rechazada en la Cámara de Diputados, la figura del delegado territorial volvió a ser introducida por la comisión que en la de Senadores se ocupó de estudiar el proyecto. Según el miembro informante de esa comisión, el senador Nogués, se había decidido reincorporar la figura del delegado territorial bajo la convicción de que su participación en el Congreso permitiría conocer mejor las necesidades que surgieran en los

59 DSCD, 1884, I, 1215. Nacido en Buenos Aires en 1830, hacia la década de 1880 Navarro Viola se encontraba entre los sectores opositores al gobierno de Roca, sobre todo en lo relativo al carácter laicista de la política educativa de este último. Junto a figuras como Emilio Lamarca formó parte de los sectores católicos con mayor protagonismo en la época. Además de desempeñarse en distintos cargos públicos, tuvo una intensa actividad en el mundo de las letras y la prensa periódica.

60 DSCD, 1884, I, 1217.

61 Idem. 
Territorios, pero además porque había sido puesta en práctica en los Estados Unidos y por lo tanto constituía un antecedente especialmente relevante para un país federal como la Argentina. ${ }^{62}$ Sin embargo, estos argumentos no fueron respaldados por la mayoría de los senadores, que finalmente se inclinaron por rechazar la incorporación del delegado territorial en la ley 1532. Las razones de esa actitud guardaban más relación con las constricciones institucionales que imponía el régimen federal que con una pura vocación restrictiva. En primer lugar, se entendía que solo las provincias podían participar en la elección de representantes a la Cámara de Diputados. Legisladores como Ramón Febre, senador por Entre Ríos, postulaban que la Constitución era taxativa al establecer que la representación en la Cámara de Diputados era exclusiva de las provincias, lo que implicaba que los Territorios solo podían obtenerla cuando fueran convertidos en provincias. ${ }^{63}$ De otro modo, dicha Cámara albergaría representaciones incongruentes que afectarían su funcionamiento.

Pero en segundo lugar, y acaso más importante, el rechazo a la incorporación del delegado territorial derivaba de que su inclusión en el Congreso implicaría una violación del principio de igualdad que debía imperar entre los representantes que conformaban cada una de las Cámaras. Como expresaba Febre, los delegados propuestos para la Cámara de Diputados «no tienen voto, que es uno de los puntos principales para venir a resolver los asuntos que se someten a la consideración de ese cuerpo» ${ }^{64}$ Esto hacía ver al delegado como un simple informante que no podría ejercer ningún tipo efectivo de representación política. Frente a la pregunta del senador por Jujuy, Pablo Carrillo, ${ }^{65}$ acerca del motivo por el que la propuesta de la comisión no otorgaba también el derecho a voto a los delegados territoriales - si es que ellos iban a dar representación a una parte

62 DSCS, 1884, 763.

63 Ibidem, 762. Febre había nacido en 1830 en la provincia de Entre Ríos, desempeñando cargos en el sistema judicial durante el gobierno de Urquiza. Desde su banca provincial, se opuso a la asunción de López Jordán como gobernador y se desempeñó en la justicia federal de Entre Ríos hasta que fue sofocada la rebelión encabezada por el último. Gobernador de Entre Ríos entre 1875 y 1879, luego integró el Senado de la nación, donde apoyó el indulto a López Jordán. Opuesto a la intervención federal a Santiago del Estero impulsada por Roca, perdió los auspicios de este para volver a ser gobernador de Entre Ríos. Cabe señalar que para esos años el nombre de Febre sonaba como acompañante de Dardo Rocha en la candidatura presidencial para 1886.

64 DSCS, 1884, 762.

65 Además de ser un gran terrateniente en Jujuy, Carrillo fue diputado nacional por dicha provincia entre 1866 y 1870 , convirtiéndose en senador nacional por la misma entre 1877 y 1886 , en el marco de la consolidación del roquismo en dicha provincia. Acerca del roquismo en Jujuy, ver Paz, 2009. 
del pueblo de la nación equivalente a las de las provincias-, Nougués se limitó a justificarla diciendo que tal cosa no podía hacerse porque «no son verdaderos representantes». ${ }^{66}$

De esta manera, la representación de los Territorios en el Congreso fue rechazada en ambas cámaras y finalmente no formó parte del diseño institucional establecido en la ley 1532. Este resultado permite observar que la legislación adoptada por la Argentina para el gobierno de sus Territorios no se explica por la sola influencia de la experiencia estadounidense. Más allá de las similitudes entre las normativas elaboradas por ambos países, diferencias sustanciales como la relativa a los delegados territoriales muestran que el orden institucional establecido en 1884 no constituía una mera reproducción del modelo norteamericano, lo que sugiere la necesidad de matizar — sin descartar - la importancia que en algunas miradas se ha dado a este último. ${ }^{67}$

\section{Conclusiones}

Según una versión muy difundida, la organización de los Territorios habría denotado la adopción de un régimen institucional contrario al federalismo. Esa caracterización parece evidenciarse en el hecho de que aquellas gobernaciones, según lo establecido en la ley de 1884, carecerían de autonomía y de representación en el Congreso de la nación. La dependencia respecto del gobierno federal, el carácter no electivo de las autoridades y la falta de participación de sus habitantes en las elecciones nacionales, darían cuenta de «elementos poco compatibles con el esquema republicano y federal». ${ }^{68}$ No obstante, los Territorios constituían al momento de su organización entidades de un carácter por entero diferente al de las provincias. No solo se trataba de espacios muy escasamente poblados - seguían siendo contemplados como desiertos-, sino que ante todo constituían entidades administrativas creadas por el propio Estado nacional. Esto significaba que no eran, como las provincias, entidades surgidas de la historia del país, sino el mero producto de una ingeniería institucional

66 DSCS, 1884, 763.

67 No es casual, en este sentido, que trabajos que concentran su mirada en la influencia que el modelo norteamericano registró en los debates en torno a la ley 1532 no ofrezcan explicaciones al hecho de que en esta última no se incluyera la figura del delegado territorial. Zusman, 2009-2010.

68 Ruffini, 2007a, 104. 
desplegada sobre un espacio imaginado como vacío. Para los legisladores que participaron en la sanción de la ley 1532, territorios despoblados y que acababan de inventarse no podían de ningún modo obtener inmediata autonomía ni representación parlamentaria. Sin embargo, esa normativa definía también un claro horizonte federal para los Territorios: debían en el futuro ser convertidos en provincias que gozarían de plena autonomía y de la correspondiente representación en el Congreso. Es posible entonces afirmar que los Territorios constituían menos una forma institucional opuesta al régimen federal que un estadio concebido para conducir la incorporación de los primeros a este último.

Esto permite cuestionar la idea de que la organización que se dio a los Territorios en 1884 expresaba sencillamente una negación del régimen federal. Más adecuado parece en cambio pensar que el problema radicaba en la existencia de formas diferentes de entender el federalismo, las cuales se traducían en la formulación de distintas propuestas de arreglo institucional. La resolución que tuvo la cuestión del delegado territorial, rechazada en dos ocasiones y finalmente no incorporada a la ley 1532, sugiere que para la mayoría de los legisladores la provincia seguía siendo concebida como la unidad fundamental de la representación política dentro del régimen federal. La idea de que los Territorios no podían contar con representación parlamentaria mientras no alcanzaran el estatus de provincia, no se muestra así como expresión de una interpretación arteramente literal de la Constitución, sino que parece responder a esa concepción según la cual las provincias eran las unidades de representación del régimen federal argentino. Ello se debía, desde esa mirada, a la preexistencia histórica de las provincias con respecto a la nación, que se entendía solo había surgido como producto de la unión entre las primeras. ${ }^{69}$

Pero los debates en torno a la ley 1532 dan cuenta también de otras formas de entender el federalismo. De manera similar a Alberdi, que aceptaba la forma de organización federal como una fatalidad histórica con la que hubiera sido preferible no lidiar, el ministro Irigoyen expresaba durante el tratamiento de aquella ley que la nación era preexistente a las provincias, lo que implicaba que la Argentina no era una federación sino que constituía una república que había adoptado la forma federativa de

69 Para legisladores como el diputado Serú, «nuestro sistema de gobierno es federal. Significa la reunión de diversos estados con cierta autonomía, con cierta independencia en su propio gobierno». DSCD, 1884, I, 1100. Esta misma concepción era sostenida por figuras como Leandro N. Alem, para quien la nación no era sino un resultado de la unión de las provincias. Gallo, 2009, 123. 
gobierno. ${ }^{70}$ Esa perspectiva, que consideraba a la nación como la unidad fundamental del federalismo argentino, había ganado amplio predicamento entre las elites políticas e intelectuales del país desde la década de $1850 .^{71}$ Desde esa mirada, la representación parlamentaria de los Territorios era necesaria no solo para conocer las necesidades de sus pobladores, sino también para asegurar la representación del pueblo de la nación en toda la extensión del país. A juzgar por la resolución que tuvo la cuestión de los delegados territoriales, esos argumentos no fueron compartidos por la mayoría de los legisladores. Aun cuando la prescriptiva constitucional establecía que la Cámara de Diputados debía representar al pueblo de la nación, la mayoría de los legisladores parecía seguir entendiendo que las provincias constituían las unidades fundamentales de representación política en el régimen federal.

Como ha señalado Botana, la consagración del federalismo en la Constitución dio al mismo el carácter de una fórmula prescriptiva siempre disponible para objetar la distribución de poder entre la nación y las provincias. ${ }^{72}$ Aun en períodos donde la dirección centralizadora de los gobiernos nacionales se mostró con más claridad, el mantenimiento del régimen federal implicaba también que las provincias siguieron contando con recursos políticos a partir de los cuales podían negociar sus relaciones con el Estado nacional y no solo aceptar una pasiva subordinación a este último. La cuestión de la delimitación de los Territorios ofrece en este sentido una experiencia sugerente, en tanto que los límites contemplados en el proyecto original fueron modificados durante el tratamiento de la ley en beneficio de algunas provincias. En esa revisión, las más beneficiadas fueron Mendoza y San Luis, dos provincias donde, como ha demostrado Paula Alonso, el roquismo había logrado construir una sólida trama de acuerdos favorable al gobierno nacional ${ }^{73}$ En este sentido, la relación entre el Estado nacional y las provincias no parece resumirse en la mera imposición del primero sobre estas últimas, sino más bien como resultante de una dinámica atravesada por la mudable configuración de las alianzas y disputas entre distintos sectores.

70 DSCD, 1884, I, 1105. Esa postura era también la que por esos años sostenía José Manuel Estrada, para quien la Argentina no era una nación formada por la agregación de estados, sino un Estado dividido en provincias. Estrada, 1895.

71 De acuerdo a Chiaramonte y Buchbinder, la idea de la preexistencia de la nación se vio fuertemente respaldada por la amplia difusión que desde mediados del siglo XIX tuvo el principio de las nacionalidades. Chiaramonte y Buchbinder, 1992.

72 Botana, 1993, 254.

73 Alonso, 2010, 106-110. 
Por último, aquella fórmula prescriptiva pesó también sobre los Territorios. La ley 1532 definió para estos un horizonte federal que, más allá de la aplicación que en las décadas siguientes se haría de dicha normativa, nunca dejó de gravitar en esas gobernaciones. La promesa de autonomía que implicaba la futura transformación de los Territorios en provincias con las mismas atribuciones que las catorce existentes, no debe ser desatendida por el hecho de que esas previsiones no se cumplieran en las décadas siguientes. Toda una compleja serie de procesos, que convendría estudiar con mayor cuidado, median entre la legislación de 1884 y los usos que de ella se hicieron en períodos posteriores, por lo que entendemos equivocado entender ese desenlace como resultado necesario de la primera. En lugar de ello, en este trabajo se ha procurado hacer el esfuerzo de distinguir entre ambos aspectos para comprender qué lugar se buscó asignar a los Territorios dentro del régimen federal de representación. En este sentido, es importante advertir que el hecho de que la ley 1532 no diera a los Territorios autonomía ni representación inmediatas puede llevar a la engañosa conclusión de que esos espacios fueron desde sus inicios concebidos como meras «colonias» destinadas a alimentar al Estado nacional, cuando en realidad la organización que en 1884 se dio a las gobernaciones preveía su transformación en provincias de pleno derecho con la sola condición de que alcanzaran una población de sesenta mil habitantes. Un requisito sin duda poco restrictivo para la obtención de autonomía.

Recibido el 5 de febrero de 2014 Aceptado el 20 de noviembre de 2014

\section{Bibliografía}

Alberdi, Juan Bautista: Bases y puntos de partida para la organización política de la República Argentina, Buenos Aires, La Cultura Argentina, 1915.

Allende, Andrés R.: «Las delimitaciones territoriales dispuestas por la Ley de 5 de octubre de 1878», Congreso Nacional de Historia sobre la Conquista del Desierto, Tomo III, Buenos Aires, Academia Nacional de la Historia, 1980, 9-18.

Alonso, Paula: Jardines secretos, legitimaciones públicas. El partido Autonomista Nacional y la política argentina de fines del siglo XIX, Buenos Aires, Edhasa, 2010. 
Arias Bucciarelli, Mario: «Tendencias en el proceso de conversión de territorios nacionales a provincias. La pervivencia de un horizonte referencial», Revista de Historia, 8, Neuquén, 1996, 131-153.

Bender, Thomas: Historia de los Estados Unidos. Una nación entre naciones. Buenos Aires, Siglo XXI, 2011.

Berhongaray, Antonio: La Pampa y su lucha por la autonomía. El fin del colonialismo interno argentino, Avellaneda, Edición del autor, 2000.

Botana, Natalio: «El federalismo liberal en Argentina: 1852-1930», en Carmagnani, Marcello (coord.), Federalismos latinoamericanos: México, Brasil, Argentina, México, FCE, 1993, 224-259.

Botana, Natalio y Gallo, Ezequiel: De la República posible a la República verdadera (1880-1910), Biblioteca del Pensamiento Argentino, Tomo III, Buenos Aires, Ariel, 1997.

Bragoni, Beatriz y Míguez, Eduardo: «De la periferia al centro: la formación de un sistema político nacional, 1852-1880», en Bragoni, Beatriz y Míguez, Eduardo (eds.), Un nuevo orden político. Provincias y Estado nacional, 1852-1880, Buenos Aires, Biblos, 2010, 9-28.

Chiaramonte, José Carlos y Buchbinder, Pablo: «Provincias, caudillos, nación y la historiografía constitucionalista argentina, 1853-1930», Anuario IEHS, 7, Tandil (Buenos Aires), 1992, 93-120.

Cutolo, Vicente Osvaldo: Nuevo Diccionario Biográfico Argentino, Buenos Aires, Editorial Elche, 1968-1985, 7 tomos.

Estrada, José Manuel: Curso de derecho constitucional, federal y administrativo. Conferencias dadas en la Universidad de Buenos Aires en los años 1877, 1878 y 1880, Buenos Aires, Compañía Sud-Americana de billetes de banco, 1895.

Farías de Foulkes, Ana Rosa: «El debate parlamentario sobre la Ley 1532 de territorios nacionales», Folia Histórica del Nordeste, 2, Resistencia (Chaco), 1976, 74-99.

Farías de Foulkes, Ana Rosa: «Organización de los Territorios Nacionales, Antecedentes y la Ley 1532 (adjudicación de la tierra y poblamiento)», en Tercer Congreso de Historia Argentina y Regional, 10-12 de julio de 1975 Santa Fe-Paraná, Tomo II, Buenos Aires, Academia Nacional de la Historia, 1977, 211-228.

Favaro, Orietta: «Realidades contrapuestas a los estados provinciales: Los territorios nacionales, 1884-1955», Realidad Económica, 144, Buenos Aires, 1996, 79-96.

Favaro, Orietta: «Transitando la especificidad de los territorios nacionales: espacios centralizados y ciudadanía restringida», en Ruffini, Martha y Masera, Ricardo Freddy (coords.), Horizontes en perspectiva. Contribuciones para la historia de Río Negro, 1884-1955, Viedma, Fundación Ameghino/ Legislatura de Río Negro, 2007, I, 25-38. 


\section{LISANDRO GALLUCCI}

Favaro, Orietta y Arias Bucciarelli, Mario: «El lento y contradictorio proceso de inclusión de los habitantes de los territorios nacionales a la ciudadanía política: un clivaje de los años '30», Entrepasados. Revista de Historia, 9, Buenos Aires, 1995, 7-26.

Gallo, Ezequiel: Alem. Federalismo y radicalismo, Buenos Aires, Edhasa, 2009.

Gibson, Edward y Falleti, Tulia: «La unidad a palos. Conflicto regional y los orígenes del federalismo argentino», Postdata. Revista de reflexión y análisis político, 12, Buenos Aires, 2007, 171-204. http://www.revistapostdata. com.ar/2012/01/la-unidad-a-palos-conflicto-regional-y-los-origenes-delfederalismo-argentino-edward-gibson-tulia-falleti/

Girbal-Blacha, Noemí: Vivir en los márgenes. Estado, políticas públicas y conflictos sociales. El Gran Chaco Argentino en la primera mitad del siglo XX, Rosario, Prohistoria, 2011.

Halperin Donghi, Tulio: Proyecto y construcción de una nación (1846-1880), Biblioteca del Pensamiento Argentino, Buenos Aires, Ariel, 1995.

Hamilton, Alexander; Madison, James y Jay, John: El Federalista, México, FCE, 2000.

Iñigo Carrera, Nicolás: La violencia como potencia económica: Chaco, 18701940, Buenos Aires, CEAL, 1988.

Leoni, María Silvia: «Los Territorios Nacionales», en Academia Nacional de la Historia, La Argentina del siglo XX, Nueva Historia de la Nación Argentina, Tomo VIII, Buenos Aires, Planeta, 2001, 43-76.

Leoni, María Silvia: «La política en los territorios nacionales argentinos. La inserción de los municipios del Chaco (1884-1951)», Revista de Historia de América, 131, México, 2002, 189-221.

Livon Grosman, Ernesto: Geografías imaginarias. El relato de viaje y la construcción del espacio patagónico, Rosario, Beatriz Viterbo Editora, 2003.

Mases, Enrique: Estado y cuestión indígena. El destino final de los indios sometidos en el sur del territorio (1878-1930), Buenos Aires, Prometeo, 2010.

Moroni, Marisa: «Fortalecer el Estado y unificar el Territorio. Organización y gobierno del Territorio Nacional de La Pampa, Argentina, a fines del siglo XIX», Boletín Americanista, LVII, 57, Barcelona, 2007, 199-218. http://www.raco.cat/index.php/BoletinAmericanista/article/view/120214/ 163462

Navarro Floria, Pedro: «La "República posible" conquista el "desierto". La mirada del reformismo liberal sobre los Territorios del Sur argentino», en Navarro Floria, Pedro (coord.), Paisajes del progreso. La resignificación de la Patagonia norte, 1880-1916, Neuquén, Educo, 2007, 191-234.

Navarro Floria, Pedro: «La mirada del reformismo liberal sobre los Territorios del Sur argentino, 1898-1916», Quinto sol, 13, Santa Rosa, 2009, 73-103. http://www.scielo.org.ar/pdf/quisol/n13/n13a03.pdf 
Oszlak, Oscar: La formación del Estado argentino. Orden, progreso y organización nacional, Buenos Aires, Ariel, 2006.

Palti, Elías José: El momento romántico. Nación, historia y lenguajes políticos en la Argentina del siglo XIX, Buenos Aires, Eudeba, 2009.

Paz, Gustavo: «El roquismo en Jujuy: notas sobre elite y política, 1880-1910», Anuario IEHS, 24, Tandil (Buenos Aires), 2009, 389-410. http://www.uni cen.edu.ar/iehs/files/Gustavo\%20L.\%20Paz\%20E1\%20Roquismo\%20en\% 20Jujuy.pdf

Pravato, Luis: «El derecho como ideología: la categoría de los territorios nacionales y la dogmática constitucional», en Quiroga, Hugo y Ruffini, Martha (eds.), Estado y Territorios Nacionales. Política y ciudadanía en Río Negro 1912-1930, Neuquén, Educo, 2011, 45-77.

Quijada, Mónica: «Nación y territorio: la dimensión simbólica del espacio en la construcción nacional argentina. Siglo XIX», Revista de Indias, LX, 219, Madrid, 2000, 373-394. http://revistadeindias.revistas.csic.es/index.php/ revistadeindias/article/view/511/578

Rebollo Paz, León: «Reseña histórica de la legislación sobre Territorios Nacionales», Segundo Congreso de Historia Argentina y Regional, Tomo III, Comodoro Rivadavia, Academia Nacional de la Historia, 1974, 83-95.

Reyna, Máximo: Territorios Nacionales. Leyes y decretos sobre su administración y resoluciones varias aplicables a los mismos, Buenos Aires, L.R. González, 1914.

Riker, William: «Federalism», en Greenstein, Fred y Polsby, Nelson (eds.), Handbook of Political Science, 5, Reading, Mass., Addison-Wesley Pub., 1975, 98-172.

Rodríguez, Fermín A.: Un desierto para la nación. La escritura del vacío, Buenos Aires, Eterna Cadencia Editora, 2010.

Ruffini, Martha: «Ciudadanía restringida para los territorios nacionales. Contradicciones en la consolidación del Estado Argentino», Estudios Interdisciplinarios de América Latina y el Caribe (EIAL), 17, 2, Tel Aviv, 2006, 61-85. http://eial.tau.ac.il/index.php/eial/article/view/464/428

Ruffini, Martha: La pervivencia de la República posible en los territorios nacionales. Poder y ciudadanía en Río Negro, Bernal, Universidad Nacional de Quilmes, 2007a.

Ruffini, Martha: «La consolidación inconclusa del Estado: los Territorios Nacionales, gobernaciones de provisionalidad permanente y ciudadanía política restringida (1884-1955)», Revista SAAP, 3, 1, Buenos Aires, 2007b, 81-101. http://www.saap.org.ar/esp/docs-revista/revista/pdf/3-1/Martha\%20 Ruffini.pdf

Ruffini, Martha: «El proceso formativo y de consolidación del Estado Argentino en perspectiva histórica. La exclusión política y sus diferentes itinerarios», en Rajland, Beatriz y Cotarelo, María Celia (eds.), La Revolución en el 
Bicentenario. Reflexiones sobre emancipación, clases y grupos subalternos, Buenos Aires, CLACSO, 2009, 169-188.

Ruffini, Martha y Pravato, Luis: «Estado, ciudadanía y representación durante la etapa territorial rionegrina (1884-1955). Perspectivas históricas y jurídicas», en Gomiz Gomiz, José Antonio y Villca, Hugo (eds.), Estado y sociedad en Río Negro hasta 1980, Viedma, Uno Editorial, 2011, 135-163.

Tocqueville, Alexis: La democracia en América, México, FCE, 2005.

Zusman, Perla: «Desierto, civilización, progreso. La Geografía del Gran Chaco y el proyecto político territorial de la formación del Estado Argentino», Ería. Revista Cuatrimestral de Geografía, 51, Oviedo, 2000, 60-67.

Zusman, Perla: «La formación del Territorio del Noroeste del río Ohio en Estados Unidos y la formación de los Territorios Nacionales en Argentina (1884). Influencias, semejanzas y diferencias», Estudios Socioterritoriales. Revista de Geografía, 8, Tandil (Buenos Aires), 2009-2010, 9-33. http://media.wix. com/ugd/59a6db_d295ddda862a4ca1a939a2e3fdb4b8a3.pdf

Zusman, Perla: «La alteridad de la nación. La formación del Territorio del Noroeste del Río Ohio de los Estados Unidos (1787) y de los Territorios Nacionales en Argentina (1884)», Documents d'anàlisi geogràfica, 56, 3, Barcelona, 2010, 503-524. http://ddd.uab.cat/pub/dag/02121573v56n3/ 02121573v56n3p503.pdf 